\title{
Consistency of spatiotemporal sound features supports the use of passive acoustics for long-term monitoring
}

\author{
E. Parmentier ${ }^{1}$ (D) L. Di lorio ${ }^{2}$, M. Picciulin ${ }^{3}$, S. Malavasi ${ }^{4}$, J.-P. Lagardère ${ }^{1}$ \& F. Bertucci ${ }^{1}$ \\ 1 Functional and Evolutionary Morphology Laboratory, AFFISH-RC, University of Liège, Liège, Belgium \\ 2 Chaire Chorus, Foundation of the Grenoble Institute of Technology, Grenoble, France \\ 3 Independent Scholar, Gorizia, Italy \\ 4 Department of Environmental Sciences, Informatics and Statistics, Ca' Foscari University of Venice, Venice, Italy
}

\section{Keywords}

fish; acoustic monitoring; sonic; Sciaenidae; conservation; sentinel species.

\section{Correspondence \\ Eric Parmentier, Functional and Evolutionary Morphology Laboratory, AFFISH-RC, University of Liège, Liège, Belgium. \\ Email: e.parmentier@ulg.ac.be \\ Editor: lain Gordon \\ Associate Editor: Vincenzo Penteriani}

Received 02 March 2017; accepted 22 May 2017

doi:10.1111/acv.12362

\begin{abstract}
Many studies stress the usefulness of fish calls as effective indicators of distinct species occurrence. However, most of these studies have been undertaken in a given area and during restricted periods of time. There is a need to show passive acoustic monitoring is a reliable method to study vocal species over space and time. This study aims to use passive acoustic methods to follow the brown meagre Sciaena umbra at relevant temporal and spatial scales. Specimens of S. umbra were recorded in both aquarium and in the field. In situ recordings were made at two regions (Corsica and Sardinia) during four summers (2008-2012-2013-2015). Temporal and frequency parameters of the fish calls were collected by different teams and compared to test the ability to unequivocally identify the fish sound. The comparison between our data and the bibliography highlights the capability to identify S. umbra during a period of 17 years in different Mediterranean regions, clearly supporting the usefulness of acoustic monitoring to discover and protect aggregation sites of this endangered species. The sound producing mechanism in S. umbra consists of high-speed sonic muscles surrounding dorsally the posterior end of the swim bladder, which can explain the low acoustic variability that helps in the species identification. Similar mechanisms are found in other Sciaenidae, suggesting that a similar conclusion can be drawn for many other adult sciaenids that could be used as sentinel species. This study should be of high interest to policymakers and scientists because it shows passive acoustic can be confidently used in resource management.
\end{abstract}

\section{Introduction}

In recent years, passive acoustic monitoring has been used as a non-invasive method to identify and monitor natural populations of fishes over long periods of time by using sound production as a reliable natural indicator to detect fish aggregation sites or to follow seasonal activities of soniferous species (Luczkovich et al., 1999; Luczkovich, Mann \& Rountree, 2008; Bertucci et al., 2015). This method has thus become a useful tool for the study of protected fishes and appears valuable for conservation efforts as monitoring sound production may support investigating different aspects of the biology of fishes (Hernandez et al., 2013; Montie, Vega \& Powell, 2015; Ruppé et al., 2015; Mooney et al., 2016). However, these studies are generally restricted to narrow regions and are time restricted. Passive acoustic monitoring is usually described as the ideal method but it lacks solid evidence about its reproducibility over time and space.
Sound production for communication purposes has been documented in a large number of marine fishes (Tricas \& Boyle, 2014; Fine \& Parmentier, 2015). Many fishes often vocalize during aggressive territorial challenges and courtship interactions in order to announce male readiness to spawn, to attract gravid females or to synchronize gamete release (Fish \& Mowbray, 1970; Ladich \& Myrberg, 2006; Myrberg \& Lugli, 2006; Montie et al., 2016). Members of the family Sciaenidae are commonly known as 'croakers' or 'drums' because of their capacities to produce loud percussive sounds (Fish \& Mowbray, 1970; Ono \& Poss, 1982; Mok \& Gilmore, 1983). Four common features seem to be found in the sciaenid calls: rapid decay of the acoustic waveform of pulses, wide bandwidth at the level of the sound spectrum, low intraspecific variability in the dominant frequency and silent periods between pulses (Parmentier et al., 2014). Both the swim bladder and sonic muscle morphologies show, however, an important interspecific diversity (Ramcharitar, Gannon \& Popper, 2006). In this fish family, sound 
production results from the fast contraction of sonic muscles that are associated to the walls of the swim bladder (Hill, Fine \& Musick, 1987; Connaughton, Fine \& Taylor, 1997). Each muscle twitch drives the damped swim bladder in a transient response (Connaughton, Taylor \& Fine, 2000; Sprague, 2000) causing multiple swim bladder oscillations that radiate sound into the surrounding water (Sprague, 2000; Lagardère \& Mariani, 2006). Because larger fish have larger muscles that take longer to contract, many sciaenid can show ontogenetic changes in call frequency (Connaughton et al., 2000; Tellechea et al., 2010).

Sciaenidae mainly occupy temperate and tropical coastal marine waters of the Atlantic, Pacific and Indian oceans. In the Mediterranean, five species have been identified: the meagre Argyrosomus regius, the brown meagre Sciaena umbra, the shi drum Umbrina cirrosa, the Canary drum Umbrina canariensis and the Fusca drum Umbrina ronchus (Chao, 1986). Among these species, vocalizations have already been studied in A. regius (Lagardère \& Mariani, 2006), S. umbra (Dijkgraaf, 1947; Bonacito et al., 2002; Codarin et al., 2012; Picciulin et al., 2012a,b) and U. cirrosa (Lagardère \& Parmentier, 2014; Picciulin et al., 2016). The brown meagre produces series of short broadband pulses with a dominant frequency of $c .270 \mathrm{~Hz}$, at night, from May to September (Picciulin et al., 2012b). Since this calling activity covers the spawning season (Chauvet, 1991; Grau, Linde \& Grau, 2009), the sounds have been considered as reproductive calls (Connaughton \& Taylor, 1995). From $S$. umbra recordings performed during the spawning season in the North Adriatic Sea, a single type of pulsed sound has been identified and is organized in different patterns, referred to as regular, irregular and chorus (Picciulin et al., 2012a, 2013).

In this study, we test the hypothesis that the sounds of $S$. umbra can be used over space and time to monitor the population. An increasing number of scientists record sounds of different fish species all around the world and argue it can help to monitor species and/or habitats. However, scientific methods need reproducibility to be universally accepted and demonstrations concerning the feasibility over space and time are important to support the use of methodologies. The objectives of this study were: (1) to further characterize the acoustic behaviour of $S$. umbra by means of passive listening techniques at different locations in the Mediterranean Sea, and (2) to describe the sound production mechanism of this species, because it can help to determine the potential variability of some acoustic characteristics (Parmentier \& Fine, 2016).

\section{Materials and methods}

\section{Acoustic recordings in tanks}

A group of 10 specimens of S. umbra weighing between 300 and $600 \mathrm{~g}$ was housed in a $7 \mathrm{~m}^{3}(2 \mathrm{~m} \times 1.9 \mathrm{~m}$ $\times 1.8 \mathrm{~m}$ ) glass tank at the Musée de la Mer in Biarritz (France). The exact place of capture of these fish in Mediterranean is not known. Recordings were made twice. First, sounds were recorded by means of a hydrophone HTI-96Min (sensitivity: $-164.4 \mathrm{~dB}$ re $1 \mathrm{~V} \mu \mathrm{Pa}^{-1}$; flat frequency response range between $2 \mathrm{~Hz}$ and $30 \mathrm{kHz}$ ) connected to a SONY TCD-D8 portable DAT recorder. These recordings were made on 7 October 2008. Subsequently, sounds were registered with a hydrophone Bruel \& Kjaer 8101 (Brüel \& Kjaer, Naerum, Denmark) connected to a measuring amplifier Bruel \& Kjaer 2610 (Fast averaging time weighting, $22.4 \mathrm{~Hz}$ high-pass frequency filter) in order to measure sound intensity (dB SPL). The hydrophone was at a distance between 0.5 and $1 \mathrm{~m}$. These recordings were made on 4 November 2008.

\section{Acoustic recordings at sea}

Recordings at sea were performed in the western part of the gulf of Calvi in Corsica (North Mediterranean Sea, France) off the research station STA.RE.S.O and in Cala Gonone, Sardina (Italy) near rocky reefs. In Corsica, the fixed recorder was placed on the ground in a near-shore rocky environment at $36 \mathrm{~m}$ water depth. Acoustic data were collected at La Revellata headland $\left(42^{\circ} 35^{\prime} \mathrm{N}\right.$; $\left.08^{\circ} 45^{\prime} \mathrm{E}\right)$ by means of a hydrophone HTI-96-Min (sensitivity: $-186 \mathrm{~dB}$ re $1 \mathrm{~V} \mu \mathrm{Pa}^{-1}$, flat frequency response range between $2 \mathrm{~Hz}$ and $30 \mathrm{kHz}$ ) connected to a Digital Spectrogram (DSG) LongTerm Acoustic Recorder (Loggerhead Instruments, Sarasota, FL, USA). Recordings were sampled at a rate of $20 \mathrm{kHz}(16$ bit resolution) and data were stored on a 32-Gb Secure Digital High Capacity (SDHC) memory card. Recordings were made in three separate years: (1) in 2008 between 7 and 13 August at the rate of $6 \mathrm{~min}$ of recording every $20 \mathrm{~min}$; (2) in 2012 from 26 June to 7 August and from 12 August to 2 October at the rate of $10 \mathrm{~min}$ every hour and (3) in the summer of 2013 from 21 June to 10 October at the rate of 5 min every hour. The Corsica recordings from 2013 were only used to describe the temporal activity throughout the summer.

In Sardinia $\left(40^{\circ} 16^{\prime} 51^{\prime \prime} \mathrm{N}\right.$; $\left.9^{\circ} 37^{\prime} 46^{\prime \prime} \mathrm{E}\right)$, acoustic data were acquired in 2015 from 14 to 17 July using a HTI-92-Min omnidirectional hydrophone (High Tech Inc., sensitivity: $-155 \mathrm{~dB}$ re $1 \mathrm{~V} / 1 \mu \mathrm{Pa} \pm 1 \mathrm{~dB}$, flat frequency response: $2 \mathrm{~Hz}-50 \mathrm{kHz}$ ) connected to a bottom-moored recorder (Songmeter SM3M; Wildlife Acoustics, Inc., Maynard, MA, USA). The recorder was placed in a near-shore rocky environment at $18 \mathrm{~m}$ water depth and acquired sounds continuously, $24 \mathrm{~h}$ a day, at a $192 \mathrm{kHz}$ sampling rate and $16 \mathrm{bit}$ resolution. In each case, distances from the hydrophone to the calling fish were unknown.

\section{Data analysis}

Acoustic analysis was performed using Avisoft SASLab Pro 4.5 software (Avisoft Bioacoustics, Glienicke, Germany). Sounds were detected by auditory and visual inspection of oscillograms and sonagrams after applying a $50-1000 \mathrm{~Hz}$ band-pass, $+10 \mathrm{~dB}$ filter. Only individual calls being clearly distinguishable from the background noise were used. The following parameters were measured: sound duration (from 
the beginning of the first pulse to the end of the last pulse), number of pulses per sound, pulse duration (not measurable in 2013 due to an elevated background noise), pulse period (peak to peak interval between two consecutive pulses) and dominant pulse frequencies (measured from logarithmic power spectra, Hamming window, FFT size: 512 points). To avoid acoustic differences induced by seasons, only calls produced during the summer months were included in the analyses. Analysis was conducted on 51 sounds recorded in tank (2008), and 56, 85, 103 and 60 recordings made in the field in Corsica 2008, Corsica 2012, Corsica 2013, and Sardinia 2015 respectively. Analysis of sounds was made by three different experimenters.

Spearman's rank correlations were used to correlate the number of pulses in a sound and the sound duration. Comparison between recording sessions (Captivity, Corsica 2008, Corsica 2012, Corsica 2013 and Sardinia 2015) was made by means of Kruskal-Wallis tests, followed by Tukey's HSD multiple comparisons tests. All analyses were two tailed, at $\alpha=0.05$ and carried out with R 3.1.2 (R Core Team 2014) using customized scripts.

As a measure of signal stereotypy, we estimated for each variable (dominant frequency, pulse period, number of pulses in a call and pulse duration) of each natural site (Revelatta 2008, 2012, 2015, Sardinia 2015 and Trieste 2012) the ratio between the inter-site coefficient of variation $(\mathrm{CVb})$ and the intra-site coefficient of variation (CVi). A low ratio $(\mathrm{CVb} /$ $\mathrm{CVi}$ ) for a given signal property is indicative of low stereotypy since acoustic parameters exhibit a much greater variation within than between sites. Therefore, low $\mathrm{CVb} / \mathrm{CVi}$ ratios reveal call consistency between the different sets of recording. (Ceugniet et al., 1999). The coefficient of variation corresponds to [(standard deviation/mean $) \times 100]$. Intrasite coefficients of variation were based on means and standard deviations calculated from the calls produced at each site. Inter-site coefficient of variation were determined on grand mean and standard deviation based on the means on all sites (Bee et al., 2001).

\section{Sonic muscle morphology}

Two female individuals (28 and $28.5 \mathrm{~cm}$ total length) and one male individual $(25.5 \mathrm{~cm}$ total length) from the Gulf of Trieste were kindly provided by Aquarium Piran (Slovenia). Fish were euthanized with an overdose of tricaine methanesulfonate (MS-222). They were then dissected in order to localize sonic muscles and describe the gross anatomy of the sound production mechanism. Sonic and epaxial muscle samples were fixed in $2.5 \%$ glutaraldehyde for $48 \mathrm{~h}$ for observation by transmission electron microscopy. Samples were then dehydrated in an ethanol-propylene oxide series and embedded in epoxy resin (SPIPON 812). Morphology was observed in 6-7 $\mu \mathrm{m}$ sections stained with toluidine blue, and the diameter of the fibres was measured. The cellular ultrastructure was examined on ultrathin sections $(60-80 \mathrm{~nm})$ stained with uranyl acetate and lead citrate. Sections were viewed with a JEOL JEM 100SX transmission electron microscope under an $80 \mathrm{kV}$ accelerating voltage.

\section{Results}

\section{Sound characteristics}

Recorded signals were multi-pulsed sounds comprising on average 5-6 pulses (Fig. 1), with a dominant frequency ranging from 240 to $330 \mathrm{~Hz}$ (Table 1). Recordings made in captivity had a mean ( \pm SE) sound pressure level of $133 \pm 3 \mathrm{~dB}$ re $1 \mu \mathrm{Pa}$ SPL.

The number of pulses in a sound showed a positive correlation with the sound duration (Spearman's rank correlations, captivity: $n=51, \quad \rho=0.98, \quad P<0.001$; Corsica 2008: $n=56, \quad \rho=0.86, \quad P<0.001 ; \quad$ Corsica 2012: $n=85$, $\rho=0.75, \quad P<0.001 ; \quad$ Corsica 2013: $n=103, \rho=0.78$, $P<0.001$; Sardinia: $n=60, \rho=0.93, \quad P<0.001)$. The pulse period duration decreased at least between the first and the fifth pulse of a sound before increasing again (Fig. 2).

Significant differences in sound duration were found between recordings: sounds were longer in captivity than at sea (Kruskal-Wallis, $\chi_{4}^{2}=90.38, P<0.001$ ). This can be explained by the duration of pulses with significantly longer pulses in sounds recorded in captivity. Likewise, sounds from 2012 showed a significantly different pulse duration (Kruskal-Wallis, $\chi_{3}^{2}=647.84, P<0.001$ ).

The pulse duration has to be considered with caution because its length is directly related to the quality of the background noise, the end of the pulse can be masked in certain circumstances and reverberation. In both the field and the tank, the pulse seems generally made of two parts (Fig. 1), which can help in future identifications of the species. The first part is of higher amplitude than the second part, which is precisely the one that can be masked in some recordings.

Although within the same range, statistical analysis indicated that the number of pulses was significantly lower in the recordings of 2008 (Kruskal-Wallis, $\chi_{4}^{2}=75.31$, $P<0.001$ ). Similarly, Pulse periods (Kruskal-Wallis, $\chi_{4}^{2}=796.8, P<0.001$ ) and dominant frequencies (KruskalWallis, $\left.\chi_{4}^{2}=730.6, P<0.001\right)$ were all statistically different between the recordings made in captivity, in Corsica in 2008, 2012 and 2013 and in Sardinia in 2015.

\section{Seasonal variation of sound characteristics}

Recordings made during the summer of 2012 (Corsica) allowed the study of the daily cycle in sound production, and analysis of the different sound features along the spawning season of the species. During 73 days, sounds were recorded at the beginning of the night, with highest acoustic activity between 21:00 and 23:00 h (Fig. 3). No sounds were recorded during daylight.

Recordings made in 2012 and 2013 were used to assess seasonal sound variation. Based on the results from 2012, the analysis of the 2013 summer concerned only all the sound files recorded around 22:00 (81 files 5 minutes duration each). The analysis of this second year concerns an uninterrupted series of 83 days. During both summers, the profile was roughly the same (Fig. 4). Sounds were produced from (at least) the end of June to the end of August. In both cases, 


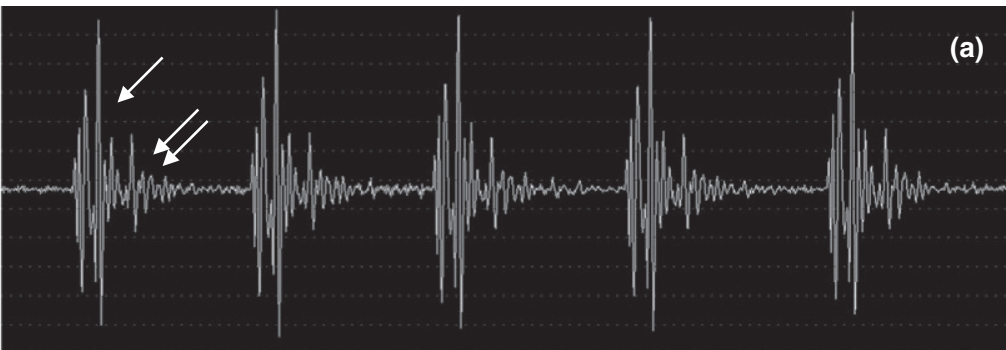

400

(b)

200

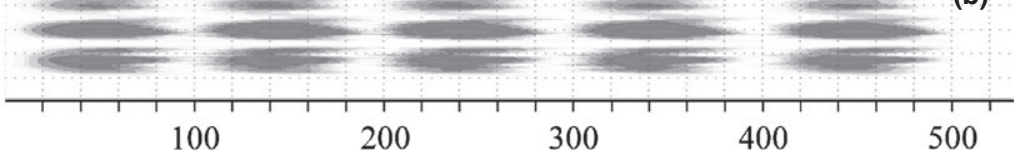

Figure 1 Oscillogram (a) and spectrogram (b) of a sound produced by Sciaena umbra, recorded in Sardinia (2015). Single arrow shows the first part of the pulse and double arrow the second part.

Table 1 Values of measured acoustic parameters in Sciaena umbra

\begin{tabular}{|c|c|c|c|c|}
\hline Recordings & Acoustic feature & $n$ & Mean \pm SD & Min-Max \\
\hline \multirow[t]{5}{*}{ Captivity } & Sound duration (ms) & 51 & $959 \pm 662$ & $33-3767$ \\
\hline & Number of pulses/sound & 291 & $6 \pm 4$ & $1-18$ \\
\hline & Pulse duration (ms) & 291 & $33 \pm 4$ & $19-59$ \\
\hline & Pulse period (ms) & 254 & $185 \pm 36$ & $93-311$ \\
\hline & Dominant frequency $(\mathrm{Hz})$ & 274 & $255 \pm 13$ & $224-312$ \\
\hline \multirow[t]{5}{*}{ Revelatta August 2008} & Sound duration (ms) & 56 & $448 \pm 160$ & $160-1023$ \\
\hline & Number of pulses/sound & 225 & $5 \pm 1$ & $1-7$ \\
\hline & Pulse duration (ms) & 220 & $16 \pm 4$ & 8-30 \\
\hline & Pulse period (ms) & 170 & $144 \pm 33$ & $105-282$ \\
\hline & Dominant frequency $(\mathrm{Hz})$ & 195 & $296 \pm 56$ & $212-665$ \\
\hline \multirow[t]{5}{*}{ Revelatta Summer 2012} & Sound duration (ms) & 85 & $548 \pm 162$ & 290-1001 \\
\hline & Number of pulses/sound & 481 & $5 \pm 1$ & 3-9 \\
\hline & Pulse duration (ms) & 299 & $16 \pm 4$ & 9-31 \\
\hline & Pulse period (ms) & 388 & $117 \pm 22$ & $80-228$ \\
\hline & Dominant frequency $(\mathrm{Hz})$ & 481 & $317 \pm 68$ & $92-473$ \\
\hline \multirow[t]{5}{*}{ Revelatta Summer 2013} & Sound duration (ms) & 103 & $567 \pm 85$ & $342-760$ \\
\hline & Number of pulses/sound & 103 & $6 \pm 1$ & 4-9 \\
\hline & Pulse duration (ms) & & - & - \\
\hline & Pulse period (ms) & 115 & $101 \pm 9$ & 88-131 \\
\hline & Dominant frequency $(\mathrm{Hz})$ & 75 & $225 \pm 38$ & $123-317$ \\
\hline \multirow[t]{5}{*}{ Cala Gonone July 2015} & Sound duration (ms) & 60 & $460 \pm 95$ & $310-691$ \\
\hline & Number of pulses/sound & 386 & $6 \pm 1$ & 4-8 \\
\hline & Pulse duration (ms) & 386 & $16 \pm 3$ & $10-22$ \\
\hline & Pulse period (ms) & 267 & $94 \pm 9$ & 77-131 \\
\hline & Dominant frequency $(\mathrm{Hz})$ & 337 & $218 \pm 28$ & $156-328$ \\
\hline \multirow[t]{5}{*}{ Gulf of Trieste 2012 (Picciulin et al., 2013) } & Sound duration (ms) & & $510 \pm 220$ & $190-1260$ \\
\hline & Number of pulses/sound & & $6 \pm 1$ & $2-15$ \\
\hline & Pulse duration (ms) & & $27 \pm 9$ & $10-50$ \\
\hline & Pulse period (ms) & & $100 \pm 19$ & $70-210$ \\
\hline & Dominant frequency $(\mathrm{Hz})$ & & $251 \pm 80$ & $111-602$ \\
\hline
\end{tabular}

calling periods became less frequent in August, before the interruption at the end of the month. No sounds were recorded during September and October in Corsica. While no significant changes were found during the summer for the number of pulses/calls (simple linear regression equation: $\left.y=0.013 x-526.43, r^{2}=0.04, P=0.07\right)$ or for the dominant frequency of pulses (simple linear regression equation: $\left.y=-0.58 x+24338, r^{2}=0.03, P=0.07\right)$, differences did appear for the pulse periods. The distributions of pulse periods were fitted by quadratic regressions and showed a decrease from the end of June to the end of July before increasing throughout August $\left(n=85, F_{2,82}=34.2-67.6, P<0.001\right)$.

The within-site and the between-site coefficients of variation ( $\mathrm{CVi}$ and $\mathrm{CVb}$ respectively) were calculated for pulse duration, number of pulses/calls, pulse period and dominant frequency (Supporting Information Table S1). In number of 
(a)
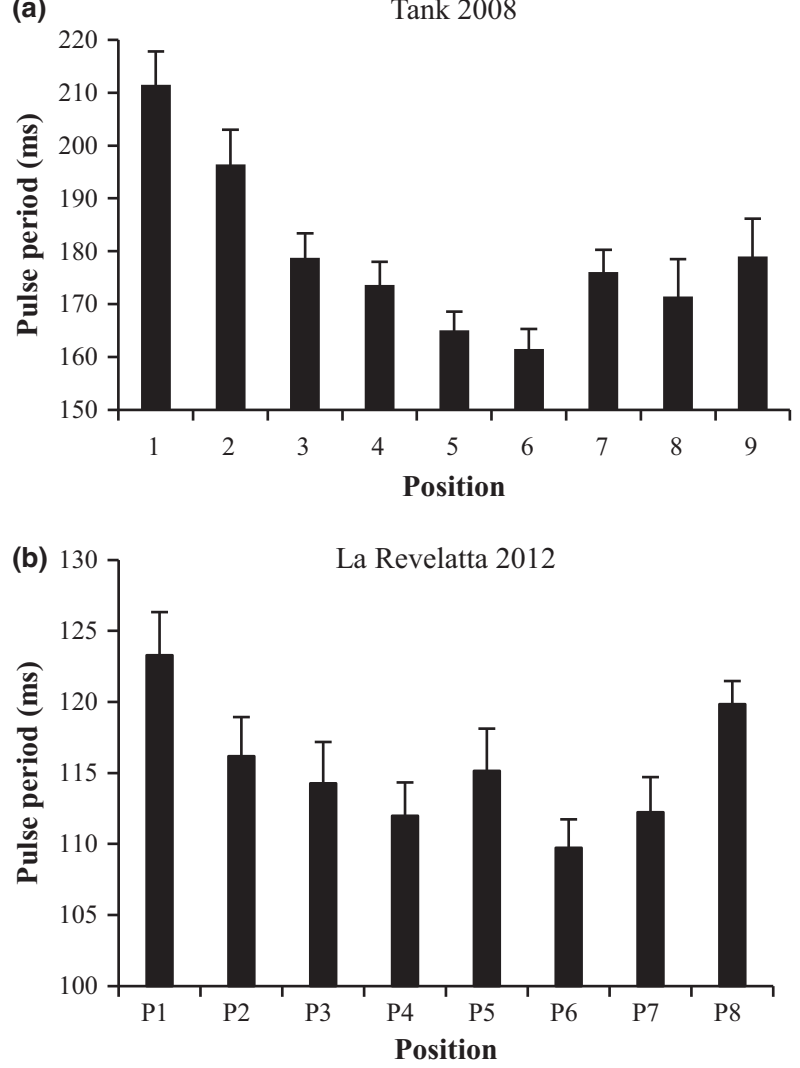

Figure 2 Graphs of the pulse periods between successive pulses within a given call in Sciaena umbra: comparison of the recordings made in tank (a) and during summer 2012 at La Revelatta (b).

pulses/calls and dominant frequency, between-site variation appeared lower than within-site variation $(\mathrm{CVb} / \mathrm{CVi}<1)$. These low ratios indicate a high consistency of these features. The ratios for pulse period and duration were slightly greater than 1 . The pulse duration ratios showed a relatively high variability (from 0.8 to 2, Supporting Information Table S1), which suggests that this parameter is more variable in this species. The higher $\mathrm{CVb} / \mathrm{CVi}$ in pulse duration could be related to differences in signal-to-noise ratio in the different sites.

\section{Sonic musculature}

The swim bladder has an oblique orientation, is large and occupies the length of the abdominal cavity. The rough anatomy of the sound producing mechanism can be compared with the one of Sciaenops ocellatus (Parmentier et al., 2014). Sonic muscles were found in males but not in females. They cover the posterior part of the swim bladder and consist of bilaterally symmetrical muscles that are perpendicular to the fish axis. These muscles originate from the abdominal hypaxial musculature and insert on a central tendon that lies dorsal to the swim bladder.

Sonic muscle fibre diameter was (mean \pm SD) $33 \pm 6 \mu \mathrm{m}$ $(n=350)$. For comparison, the white muscle fibre diameter in the same species is $89 \pm 30 \mu \mathrm{m}(n=85)$. Muscle cells

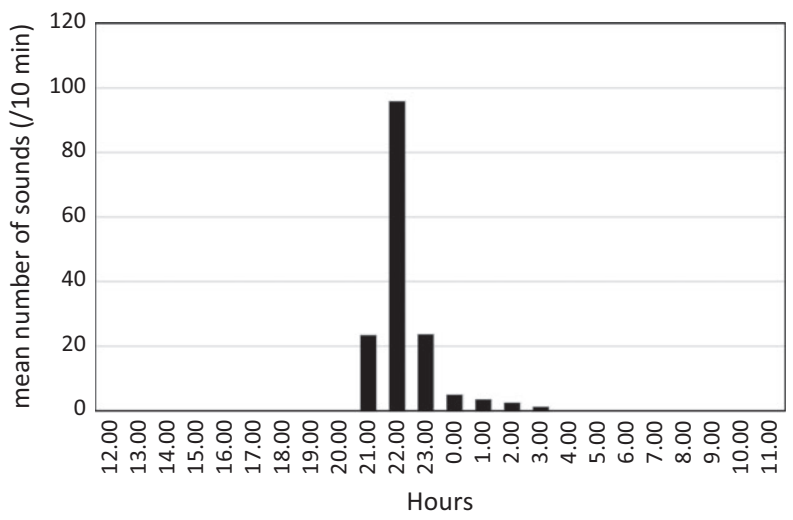

Figure 3 Graphic representation of the sound production daily pattern of Brown meagre Sciaena umbra, recorded in Corsica (Gulf of Calvi) in 2012. The figure depicts the mean number of calls of the first $10 \mathrm{~min}$ of each hour. This graph is based on the analysis of a series of 73 days.

comprise alternating ribbons of sarcoplasmic reticulum and myofibrils, whereas mitochondria are mainly found at the periphery, just behind the sarcolemma (Fig. 5). Some mitochondria can, however, be found in the central core of the cell. In S. umbra, the area of the myofibrils was c. $48 \%$.

\section{Discussion}

This study aimed to investigate spatiotemporal variation and morphological aspects of the sound production in the brown meagre. In our recordings in the field (Corsica 2008, 2012 and 2013, Sardinia 2015), sounds of S. umbra consist of successive low-frequency pulses with a mean dominant frequency of $200-300 \mathrm{~Hz}$, a pulse period of $c$. 95-145 ms and a pulse duration of $c .16 \mathrm{~ms}$ (Table 1). The progressive decrease in the first four pulse periods within S. umbra calls (Fig. 2) and the pulse made of two parts should help to identify $S$. umbra from other Mediterranean sciaenid species (A. regius, $U$. cirrosa, $U$. canariensis and $U$. ronchus). An exhaustive comparison is however not yet feasible since sounds were never recorded in three species. The differences at the level of call duration and period found between sounds recorded in captivity and sounds recorded in the wild were also found in $S$. ocellatus and are known to be related to tank-based recordings (Parmentier et al., 2014).

The acoustic features of the calls from the Ligurian and Tyrrhenian Seas (Corsica and Sardinia) described here show strong similarities to previously reported studies from the Adriatic sea (Bonacito et al., 2001; Picciulin et al., 2012a), where calls averaged six pulses having a pulse period of $100 \mathrm{~ms}$ and a mean peak frequency of $c .270 \mathrm{~Hz}$. In addition to the similarity of calls recorded in different geographic locations, S. umbra calls also exhibit a long-term stability of call characteristics over time since some of these recordings were separated by a period of 17 years.

It is worth commenting on the consistency of the sounds despite the statistical results. Sampling and environmental conditions can easily explain most of the sound features that 
(a)

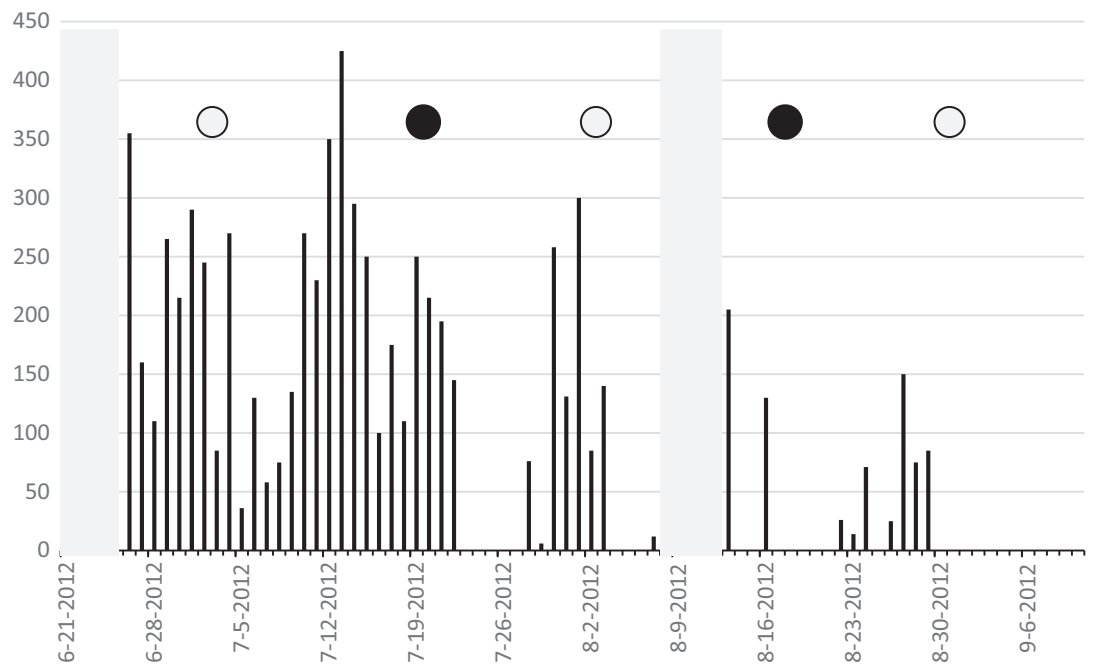

(b)

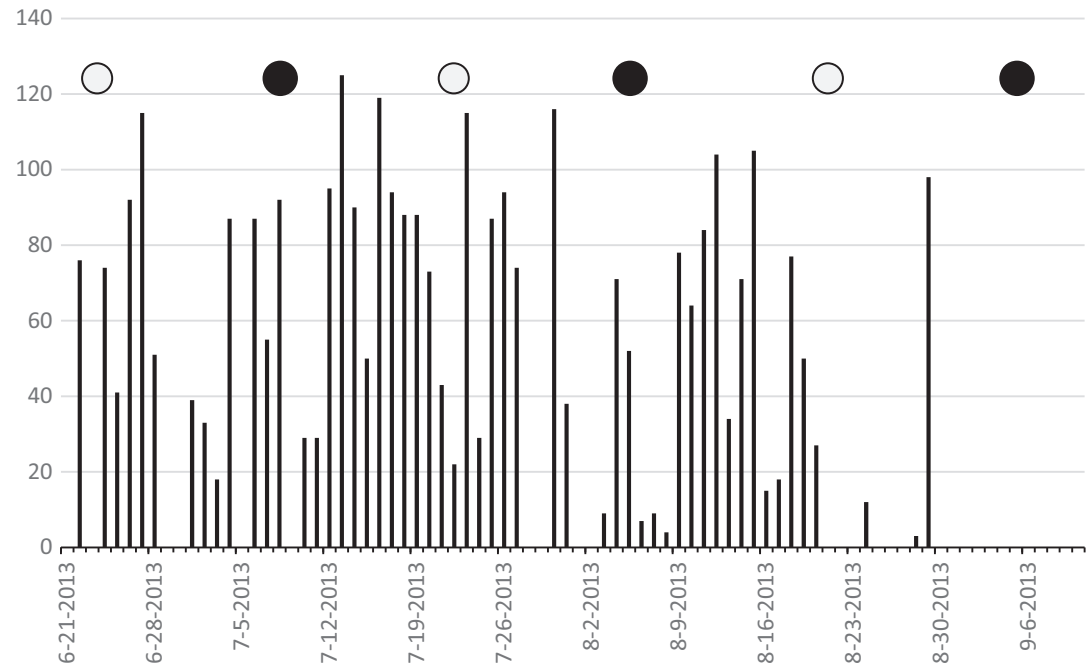

Figure 4 Daily sound production of Sciaena umbra and moon cycle at La Revellata in 2012 (a) and 2013 (b). Number of sounds is given for $10 \mathrm{~min}^{-1}$ (a) and $5 \mathrm{~min} \mathrm{~h}^{-1}$ (b). Sounds were not recorded during the greyish periods in 2012. Black circle: new moon, grey circle: full moon.

were statistically different. In the field, sounds were recorded by different hydrophones, at different periods of the year and at an unknown distance from the fish, meaning that the background noise, that determines the amplitude of the signal-to-noise ratio, directly affects the sound duration measurement. In S. umbra calls, the period duration between consecutive pulses is not regular and varies according to its place in the call and to the number of pulses. This means that the number of pulses affects the mean duration of the period. Moreover, the number of pulses can vary according to the time of the day (Picciulin et al., 2012b). Despite these differences, different researchers were independently able to identify calls (Table 1) of S. umbra, which suggests we can be confident in the unique characteristics of acoustic features for future studies using passive acoustics. In the study of vocalizations, the $\mathrm{CVb} / \mathrm{CVi}$ ratio is usually used to define the potential for individual identity coding (Ceugniet et al., 1999; Bee et al., 2001; Lengagne, 2001; Budka \& Osiejuk, 2013). Here we analysed differences between and within sites and not individuals. In the comparisons of the different sites, the $\mathrm{CVb} / \mathrm{CVi}$ ratio is relatively low (Supporting Information Table S1), which indicates vocal similarities between individuals of the different sites. It means acoustic properties may fail to identify the different sites because of limited variability (Gerhardt, 1991). This result reinforces the consistency of the call and its specific affiliation. Interestingly, the pulse period is more variable and is precisely the acoustic feature that most contribute to discriminate among males (Amorim et al., 2011). The pulse duration variation can also be high but is less interesting because highly related to the signal-to-noise ratio.

This consistency in $S$. umbra calls could be explained by the kind of sound producing mechanism involved. In adults, 

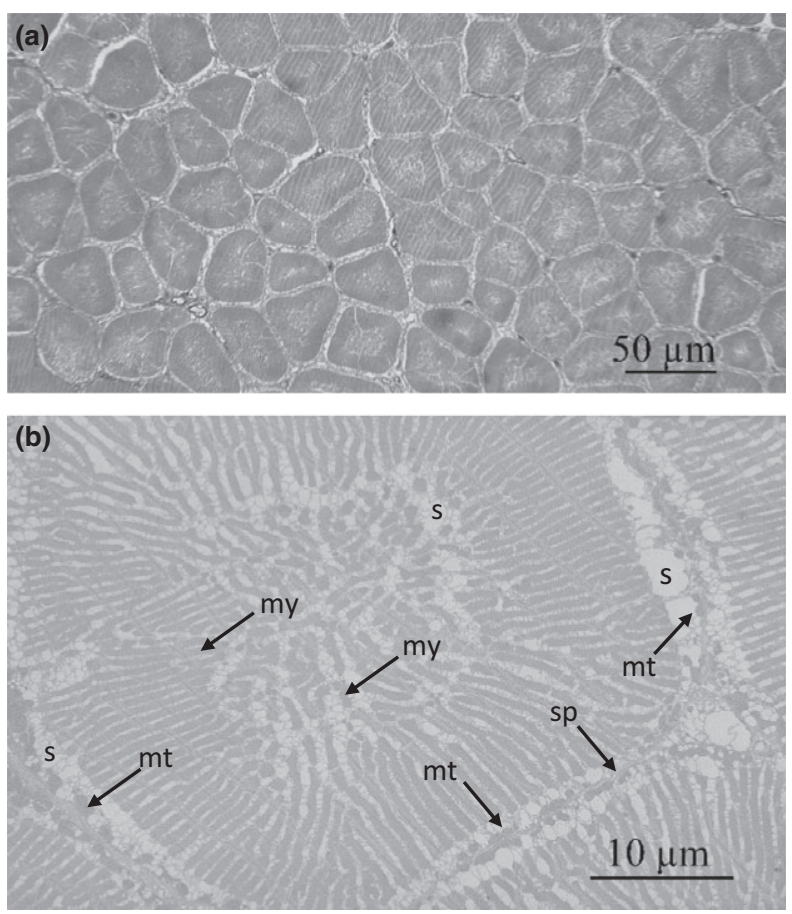

Figure 5 Semi-thin (a) and transmission electron microscopy (b) sections of the sonic muscle in Sciaena umbra. Mt, mitochondrium; my, myofibril; s, sarcoplasm; sa, sarcolemma.

high-speed sonic muscles acting on the swim bladder do not allow wide variability because the ability to make sound is under physiological muscle constraints (Millot, Vandewalle \& Parmentier, 2011). As in other sciaenids, the anatomy and muscle ultrastructure perfectly reflect that these sounds are produced by the identified high-speed swim bladder muscles. The comparison with other taxa indicates that the ratio occupied by myofibril area relative to the total muscle fibre cross-section can be indicator of the drumming muscle. Sciaena umbra, different catfish species and piranhas are all able to realize high-speed contractions (Boyle, Colleye \& Parmentier, 2014; Millot \& Parmentier, 2014; Boyle, Bolen \& Parmentier, 2015a; Boyle et al., 2015b) and all have in cross-section a myofibril area that corresponds to between 45 and $60 \%$ of the muscle cell diameter. In comparison, this ratio corresponds to $76 \%$ in the white epaxial muscle in Pygocentrus nattereri (Millot \& Parmentier, 2014) and is around $80 \%$ in S. umbra (E. Parmentier, pers. obs.). In sciaenid species, a single pulse corresponds to a unit of muscle activity (Tower, 1908; Sprague, 2000; Connaughton, Fine \& Taylor, 2002; Parmentier et al., 2014). In these fishes, the twitch is assumed to produce individual pulses with the cycle of each pulse giving the dominant frequency of the sound (Lagardère \& Mariani, 2006). In species having their sound-producing mechanism based on superfast muscles, the slope of the relationship between dominant frequency and fish size in adult specimens is between -1 and $-10^{\circ}$ (Parmentier \& Fine, 2016). It means the size effect on the call frequency is minor and is most probably not important in the fish biology. In this case, the female choice of partner would not be related to the call frequency but to the number of calls produced per time unit or the number of pulses per call (Amorim et al., 2010, 2013; Vasconcelos et al., 2012; Pedroso et al., 2013). This kind of sexual selection does not favour variation in the frequency or pulse period. Because the frequency is less variable in adults at least (Tellechea et al., 2010), it means that data related with frequency are more reliable than in fishes using other kinds of mechanisms (e.g. damselfish, tilapias, gobies, etc.). In S. umbra, the sound production rate might convey information about male status and spawning readiness to females (Amorim, Fonseca \& Almada, 2003; Picciulin et al., 2013).

Sound production occurred (or was at least detected) mainly between 21:00 and 23:00 h in Corsica and Sardinia. In the Adriatic sea, calling activity was present between 18:00 and 08:00 $\mathrm{h}$ with a peak between 18:00 and 01:00 $\mathrm{h}$ (Picciulin et al., 2013). Increased sound production during the first period of the night is very common in sciaenid species (Fish \& Cummings, 1972; Saucier \& Baltz, 1993; Mann, Bowers-Altman \& Rountree, 1997; Mann \& Grothues, 2009). Sounds could be used to locate mates and evening spawning is advantageous for egg dispersal (Holt, Holt \& Arnold, 1985; Tellechea, Fine \& Norbis, 2017). As in the red drum S. ocellata (Guest \& Lasswell, 1978) and the shi drum $U$. cirrosa (Francescon \& Barbaro, 1999), $S$. umbra males produce sounds during courtship while swimming after the females (Picciulin et al., 2012a). Morphological data reinforce this hypothesis because sonic muscles are found only in males. Gonads of the brown meagre mature from April to June in parallel to a spawning season extending from May to August (Chakroun-Marzouk \& Ktari, 2003; Engin \& Seyhan, 2009; Grau et al., 2009). Spring recordings should be carried out in order to acoustically determine the beginning of the spawning season.

The analysis of the seasonal variation in $S$. umbra calling activity reinforces our assumption the sounds could help to define the spawning season. First, the acoustic activity is more important during June and July than August which corresponds to the end of the spawning season. Second, the great variation in the amount of calls found between consecutive days (Fig. 4) could be related to the lack of synchronization in gonadal development within the fish groups since the breeders within one population do not show the same ovarian maturity stage at the same time (Grau et al., 2009), which is a way to expand the population's overall spawning season.

\section{Conclusion}

The consistency of S. umbra sound features over years and locations, as well as the role that sound production plays in reproduction, strongly supports the use of passive acoustic monitoring to follow this vulnerable species (Bonacito et al., 2002; Codarin et al., 2012; Picciulin et al., 2012a). Within the context of the French moratorium that bans fishing (commercial and recreational) of the brown merge from 2014 to the end of 2018, hydrophones can be deployed to localize the species at different sites across the Mediterranean Sea, to identify reproduction areas, to 
monitor restoration of overfished areas and spawning sites and to define conservation areas in time and space. Moreover, the strong site-fidelity, known to occur at least during out the spawning period (Alós \& Cabanellas-Reboredo, 2012), combined with the species long lifespan (18 years) allows for the establishment of long-term research, monitoring and management plans across populations. Finally, since the sound-producing mechanism of $S$. umbra is also found in other sciaenid species, similar conclusions can likely be drawn for many other species.

\section{Funding}

This work was performed during a postdoctoral stay of F. Bertucci in Liège, funded by a study grant from the Fyssen Foundation. L. Di Iorio received support from the SEACOUSTIC project, co-funded by the RMC Water Agency (France). E. Parmentier was funded by F.R.S. - FNRS (T.00056.13). The authors are grateful to M. Fine and a second anonymous referee for their suggestions, which contributed to the improvement of the present paper.

\section{Conflict of interest}

Authors do not declare conflicts of interest.

\section{Ethical approval}

All applicable international, national and/or institutional guidelines for the care and use of animals were followed.

\section{Acknowledgements}

The authors would like to thank the team of the STA.RE.S.O. for its technical support in Corsica, and BluBest (P. Insolera) and E. Di Iorio in Sardinia. Many thanks to Marie Bournonville and all the technicians of the Liège Museum-Aquarium, and to people of the Musée de la mer of Biarritz. A particular mention to Valter Žiža (Aquarium Piran, Slovenia) and to Bruno Parmentier for helping in fish transportation. The authors are grateful to M. Fine and a second anonymous referee for their suggestions, which contributed to the improvement of the present paper.

\section{References}

Alós, J. \& Cabanellas-Reboredo, M. (2012). Experimental acoustic telemetry experiment reveals strong site fidelity during the sexual resting period of wild brown meagre, Sciaena umbra. J. Appl. Ichthyol. 28, 606-611.

Amorim, M.C.P., Fonseca, P.J. \& Almada, V.C. (2003). Sound production during courtship and spawning of Oreochromis mossambicus : male - female and male - male interactions. J. Fish Biol. 62, 658-672.

Amorim, M.C.P., Simoes, J.M., Mendonça, N., Bandarra, N.M., Almada, V.C. \& Fonseca, P.J. (2010). Lusitanian toadfish song reflects male quality. J. Exp. Biol. 213, 2997-3004.
Amorim, M.C.P., Simões, J.M., Almada, V.C. \& Fonseca, P.J. (2011). Stereotypy and variation of the mating call in the Lusitanian toadfish, Halobatrachus didactylus. Behav. Ecol. Sociobiol. 65, 707-716.

Amorim, M.C.P., Pedroso, S.S., Bolgan, M., Jordão, J.M., Caiano, M. \& Fonseca, P.J. (2013). Painted gobies sing their quality out loud: acoustic rather than visual signals advertise male quality and contribute to mating success. Funct. Ecol. 27, 289-298.

Bee, M.A., Kozich, C.E., Blackwell, K.J. \& Gerhardt, H.C. (2001). Individual variation in advertisement calls of territorial male green frogs, Rana clamitans: implications for individual discrimination. Ethology 107, 65-84.

Bertucci, F., Lejeune, P., Payrot, J. \& Parmentier, E. (2015). Sounds produced by the dusky grouper (Epinephelus marginatus) during its spawning season in the Mediterranean Sea. J. Fish Biol. 87, 400-421.

Bonacito, C., Costantini, M., Picciulin, M., Ferrero, E.A. \& Hawkins, A.D. (2001). Acoustical and temporal features of Sciaena umbra (Sciaenidae) in the Miramare marine reserve (Gulf of Trieste, Italy). In Proceeding of the XVIII

IBAC, International Bioacoustics Council Meeting, Cogne.

Bonacito, C., Costantini, M., Picciulin, M., Ferrero, E.A. \& Hawkins, A.D. (2002). Passive hydrophone census of Sciaena umbra (Sciaenidae) in the Gulf of Trieste (Northern Adriatic sea, Italy). Bioacoustics 12, 292-294.

Boyle, K.S., Colleye, O. \& Parmentier, E. (2014). Sound production to electric discharge: sonic muscle evolution in progress in Synodontis spp. catfishes (Mochokidae). Proc. $R$. Soc. B Biol. Sci. 281, 1197.

Boyle, K.S., Bolen, G. \& Parmentier, E. (2015a). Agonistic sounds and swim bladder morphology in a malapterurid electric catfish. J. Zool. (Lond.) 296, 249-260.

Boyle, K.S., Riepe, S., Bolen, G. \& Parmentier, E. (2015b). Variation in swim bladder drumming sounds from three doradid catfish species with similar sonic morphologies. J. Exp. Biol. 218, 2881-2891.

Budka, M. \& Osiejuk, T.S. (2013). Formant frequencies are acoustic cues to caller discrimination and are a weak indicator of the body size of corncrake males. Ethology 119, 960-969.

Ceugniet, M., Aubin, T., Bernard-Laurent, A. \& Soyez, D. (1999). Vocal signatures of the rally call of red-legged and rock partridges and of their hybrids. C.R. Acad. Sci. 322, 887-895.

Chakroun-Marzouk, N. \& Ktari, M.H. (2003). Le corb des côtes tunisiennes Sciaena umbra (Sciaenidae): cycle sexuel, âge et croissance. Cybium 27, 211-225.

Chao, L.N. (1986). Sciaenidae. In Fishes of the Eastern Atlantic and Mediterranean: 865-874. Whitehead, P.J.P., Bauchot, M.-L., Hureau, J.C. \& Tortonese, E. (Eds). Paris: UNESCO.

Chauvet, C. (1991). Le corb ou brown meagre (Sciaena umbra - Linnaeus, 1758) quelques éléments de sa biologie. In Les Espèces Marines à Protéger en Méditerranée: 229-231. Boudouresque, C.F., Avon, M. \& Gravez, V. (Eds). France: GIS Posidonie. 
Codarin, A., Picciulin, M., Sebastianutto, L., Calcagno, G., Spoto, M. \& Ferrero, E.A. (2012). Nocturnal acoustic activity in the shallow waters of WWF-Miramare Natural Marine Reserve (Trieste, Italy). In Effects of Noise on Aquatic Life, Advances in Experimental Medicine and Biology, 730: 161-164. Popper, A.N. \& Hawkins, A.D. (Eds). New York: Springer Science + Business Media, LLC.

Connaughton, M.A. \& Taylor, M.H. (1995). Seasonal and daily cycles in sound production associated with spawning in weakfish, Cynoscion regalis. Environ. Biol. Fishes 42, 233-240.

Connaughton, M.A., Fine, M.L. \& Taylor, M.H. (1997). The effects of seasonal hypertrophy and atrophy on fiber morphology, metabolic substrate concentration and sound characteristics of the weakfish sonic muscle. J. Exp. Biol. 200, 2449-2457.

Connaughton, M.A., Taylor, M.H. \& Fine, M.L. (2000). Effects of fish size and temperature on weakfish disturbance calls: implications for the mechanism of sound generation.

J. Exp. Biol. 203, 1503-1512.

Connaughton, M.A., Fine, M.L. \& Taylor, M.H. (2002). Weakfish sonic muscle: influence of size, temperature and season. J. Exp. Biol. 205, 2183-2188.

Dijkgraaf, S. (1947). Ein Tone erzeugender Fisch im Neapler Aquarium. Experientia 3, 493-494.

Engin, S. \& Seyhan, K. (2009). Biological characteristics of rock goby, Gobius paganellus (Actinopterygii: Perciformes: Gobiidae), in the south-eastern Black sea. Acta Ichthyol. Piscat. 39, 111-118.

Fine, M.L. \& Parmentier, E. (2015). Mechanisms of sound production. In Sound communication in fishes: 77-126. Ladich, F. (Ed). Wien: Springer.

Fish, J.F. \& Cummings, W.C. (1972). A 50-dB increase in sustained ambient noise from fish (Cynoscion xanthulus). J. Acoust. Soc. Am. 52, 1266-1270.

Fish, M.P. \& Mowbray, H.M. (1970). Sounds of Western North Atlantic Fishes. Baltimore: The Johns Hopkins Press.

Francescon, A. \& Barbaro, A. (1999). Umbrina cirrosa produzione e allevamento in cattività. Manuale di divulgazione, Serie Acquacultura. Verona: Veneto Agricoltura. Corella Poligrafica.

Gerhardt, H.C. (1991). Female mate choice in treefrogs: static and dynamic acoustic criteria. Anim. Behav. 42, 615-635.

Grau, A., Linde, M. \& Grau, A.M. (2009). Reproductive biology of the vulnerable species Sciaena umbra Linnaeus, 1758 (Pisces: Sciaenidae). Sci. Mar. 73, 67-81.

Guest, W.C. \& Lasswell, J.L. (1978). A note on courtship behavior and sound production of Red Drum. Copeia 1978, 337-338.

Hernandez, K.M., Risch, D., Cholewiak, D.M., Dean, M.J., Hatch, L.T., Hoffman, W.S., Rice, A.N., Zemeckis, D. \& Van Parijs, S.M. (2013). Acoustic monitoring of Atlantic cod (Gadus morhua) in Massachusetts Bay: implications for management and conservation. ICES J. Mar. Sci. J. du Cons. 70, 628-635.
Hill, G.L., Fine, M.L. \& Musick, J.A. (1987). Ontogeny of the sexually dimorphic sonic muscle in three sciaenid species. Copeia 3, 708-713.

Holt, G.J., Holt, S.A. \& Arnold, C.R. (1985). Diel periodicity of spawning in sciaenids. Mar. Ecol. Prog. Ser. 27, 1-7.

Ladich, F. \& Myrberg, A.A.J. (2006). Agonistic behavior and acoustic communication. In Communication in fishes: 122-148. Ladich, F., Collin, S.P., Moller, P. \& Kapoor, B.G. (Eds). Enfield: Science Publishers.

Lagardère, J.P. \& Mariani, A. (2006). Spawning sounds in meagre Argyrosomus regius recorded in the Gironde estuary, France. J. Fish Biol. 69, 1697-1708.

Lagardère, J.-P. \& Parmentier, É. (2014). Les sons de contact de l'ombrine côtière - Umbrina cirrosa (Linné, 1758). Bull. Soc. Borda 514, 214-217.

Lengagne, T. (2001). Temporal stability in the individual features in the calls of eagle owls (Bubo bubo). Behaviour 138, 1407-1419.

Luczkovich, J.J., Sprague, M.W., Johnson, S.E. \& Pullinger, R.C. (1999). Delimiting spawning areas of weakfish, Cynoscion regalis (family Sciaenidae) in Pamlico Sound, North Carolina using passive hydroacoustic surveys. Bioacoustics 10, 143-160.

Luczkovich, J.J., Mann, D.A. \& Rountree, R.A. (2008). Passive acoustics as a tool in fisheries science. Trans. Am. Fish. Soc. 137, 533-541.

Mann, D.A. \& Grothues, T.M. (2009). Short-term upwelling events modulate fish sound production at a mid-Atlantic ocean observatory. Mar. Ecol. Prog. Ser. 375, 65-71.

Mann, D.A., Bowers-Altman, J. \& Rountree, R.A. (1997). Sounds produced by the striped cusk-eel Ophidion marginatum (Ophidiidae) during courtship and spawning. Copeia 3, 610-612.

Millot, S. \& Parmentier, E. (2014). Development of the ultrastructure of sonic muscles : a kind of neoteny? BMC Evol. Biol. 14, 1-9.

Millot, S., Vandewalle, P. \& Parmentier, E. (2011). Sound production in red-bellied piranhas (Pygocentrus nattereri, Kner): an acoustical, behavioural and morphofunctional study. J. Exp. Biol. 214, 3613-3618.

Mok, H.K. \& Gilmore, R.G. (1983). Analysis of sound production in estuarine aggregations of Pogonias cromis, Bairdiella chrysoura, and Cynoscion nebulosus (Sciaenidae). Bull. Inst. Zool. Acad. Sin. 22, 157-186.

Montie, E.W., Vega, S. \& Powell, M. (2015). Seasonal and spatial patterns of fish sound production in the May River, South Carolina. Trans. Am. Fish. Soc. 144, 705-716.

Montie, E.W., Kehrer, C., Yost, J., Brenkert, K., O’Donnell, T. \& Denson, M. R. (2016). Long-term monitoring of captive red drum Sciaenops ocellatus reveals that calling incidence and structure correlate with egg deposition. $J$. Fish Biol. 88, 1776-1795.

Mooney, T.A., Kaplan, M.B., Izzi, A., Lamoni, L. \& Sayigh, L. (2016). Temporal trends in cusk eel sound production at a proposed US wind farm site. Aquat. Biol. 24, 201-210. 
Myrberg, J.A.A. \& Lugli, M. (2006). Reproductive behavior and acoustic communication. In Communication in Fishes: 149-176. Ladich, F., Collin, S.P., Moller, P. \& Kapoor, B.G. (Eds). Endfield: Science Publishers.

Ono, R.D. \& Poss, S.G. (1982). Structure and innervations of the swimbladder musculature in the weakfish, Cynoscion regalis (Teleostei: Sciaenidae). Can. J. Zool. 60, 19551967.

Parmentier, E. \& Fine, M.L. (2016). Fish sound production: insight. In Vertebrate sound production and acoustic communication: 19-49. Suthers, R., Tecumseh, F., Popper, A.N. \& Fay, R.R. (Eds). New York: Springer.

Parmentier, E., Tock, J., Falguière, J.-C. \& Beauchaud, M. (2014). Sound production in Sciaenops ocellatus: preliminary study for the development of acoustic cues in aquaculture. Aquaculture 432, 204-211.

Pedroso, S.S., Barber, I., Svensson, O., Fonseca, P.J. \& Amorim, M.C.P. (2013). Courtship sounds advertise species identity and male quality in sympatric Pomatoschistus spp. gobies. PLOS ONE 8, e64620.

Picciulin, M., Calcagno, G., Sebastianutto, L., Bonacito, C., Codarin, A., Constantini, M. \& Ferrero, E.A. (2012a). Diagnostics of nocturnal calls of Sciaenia umbra (L., fam. Sciaenidae) in a near shore Mediterranean marine reserve. Bioacoustics 2012, 1-12.

Picciulin, M., Sebastianutto, L., Codarin, A., Calcagno, G. \& Ferrero, E.A. (2012b). Brown meagre vocalization rate increases during repetitive boat noise exposures: a possible case of vocal compensation. J. Acoust. Soc. Am. 132, 3118 3124.

Picciulin, M., Bolgan, M., Codarin, A., Fiorin, R., Zucchetta, M. \& Malavasi, S. (2013). Passive acoustic monitoring of Sciaena umbra on rocky habitats in the Venetian littoral zone. Fish. Res. 145, 76-81.

Picciulin, M., Bolgan, M., Coro, A.B., Calcagno, G. \& Malavasi, S. (2016). Sound production by the Shi drum Umbrina cirrosa and comparison with the brown meagre Sciaena umbra: a passive acoustic monitoring perspective. J. Fish Biol. 88, 1655-1660.

R Core Team (2014). R: a language and environment for statistical computing. R Foundation for Statistical Computing. Vienna, Austria. Available at: http://www. R-project.org/.
Ramcharitar, J.U., Gannon, D.P. \& Popper, A.N. (2006). Bioacoustics of fishes of the family Scianidae (croackers and drums). Trans. Am. Fish. Soc. 135, 1409-1431.

Ruppé, L., Clément, G., Herrel, A., Ballesta, L., Décamps, T., Kéver, L. \& Parmentier, E. (2015). Environmental constraints drive the partitioning of the soundscape in fishes. Proc. Natl Acad. Sci. USA 112, 6092-6097.

Saucier, M.H. \& Baltz, D.M. (1993). Spawning site selection by spotted seatrout, Cynoscion nebulosus, and black drum, Pogonias cromis, in Louisiana. Environ. Biol. Fishes 36, 257-272.

Sprague, M.W. (2000). The single sonic muscle twitch model for the sound-production mechanism in the weakfish, Cynoscion regalis. J. Acoust. Soc. Am. 108, 2430-2437.

Tellechea, J.S., Martinez, C., Fine, M.L. \& Norbis, W. (2010). Sound production in the whitemouth croaker and relationship between fish size and disturbance call characteristics. Environ. Biol. Fishes 89, 163-172.

Tellechea, J.S., Fine, M.L. \& Norbis, W. (2017). Passive acoustic monitoring, development of disturbance calls and differentiation of disturbance and advertisement calls in the Argentine croaker Umbrina canosai (Sciaenidae). J. Fish Biol. 90, 1631-1643.

Tower, R.W. (1908). The production of sound in the drumfishes, the searobin and the toadfish. Ann. N. Y. Acad. Sci. 18, 149-180.

Tricas, T. \& Boyle, K. (2014). Acoustic behaviors in Hawaiian coral reef fish communities. Mar. Ecol. Prog. Ser. 511, $1-16$.

Vasconcelos, R.O., Carriç̧o, R., Ramos, A., Modesto, T., Fonseca, P.J. \& Amorim, M.C.P. (2012). Vocal behavior predicts reproductive success in a teleost fish. Behav. Ecol. 23, 375-383.

\section{Supporting information}

Additional Supporting Information may be found in the online version of this article at the publisher's web-site:

Table S1. Within- and between-site coefficients of variation (CVi and $\mathrm{CVb}$ respectively) calculated for different acoustic parameters in Sciaena umbra. 